\title{
Facultative polyandry and the role of infant-carrying in wild saddle-back tamarins (Saguinus fuscicollis)
}

\author{
Anne Wilson Goldizen \\ Department of Biology, University of Michigan, Ann Arbor, MI 48109, USA \\ Received March 24, 1986 / Accepted November 9, 1986
}

Summary. Wild saddle-back tamarins (Saguinus fuscicollis) in southeastern Peru have a variable mating system that can differ both between territories at any one time and within territories over time. Groups are usually monogamous or cooperatively polyandrous, but are occasionally even polygynous. This study addressed the following questions: Why does this population contain both monogamous and polyandrous groups simultaneous$1 y$ ? What factors determine whether specific groups are monogamous or polyandrous? The data from this study population tentatively support the hypothesis that adults should mate monogamously only if they have nonreproductive helpers (usually older offspring) to help rear infants. Without helpers, the reproductive success of both males and females is hypothesized to be higher, on average, if they mate polyandrously than if they mate monogamously. The proposed benefits of polyandry to males and females differ quantitatively, but in both cases benefits stem from the help that males provide in rearing young. The following results support this hypothesis. (1) Lone pairs were never seen to attempt breeding, and calculations suggest that the costs of lactation and infant-carrying are too great for lone pairs to have a high probability of being able to raise twin offspring (the normal litter size). (2) Polyandrous males and nonreproductive offspring contributed substantially to infant care, particularly infant-carrying (Fig. 2). (3) Adult males carried infants approximately twice as often as did lactating females, presumably because of the combined costs of (a) lactation (Fig. 3) and (b) infant-carrying (Fig. 4). The proximate causes of cooperative polyandry in $S$. fuscicollis appear to be different from those responsible in several bird species, showing that cooperative polyandry is a complex phenomenon.

\section{Introduction}

Faaborg et al. (1980) and Faaborg and Patterson (1981) coined the term "cooperative polyandry" to describe groups in which two or more males copulate with a single female during a single breeding season and then cooperate to raise the female's subsequent offspring. Cooperatively polyandrous groups have been described in several bird species (e.g., Maynard Smith and Ridpath 1972; Ridpath 1972; Mader 1979; Stacey 1979; Faaborg et al. 1980; Davies 1983; Joste et al. 1985; Davies and Lundberg 1984). In each of these species both polyandrous and monogamous groups occur, but the proximate determinants of the mating systems of individual groups appear to be different for each species. For example, Maynard Smith and Ridpath (1972) suggested that Tasmanian native hen (Tribonyx mortierii) males should form polyandrous trios with their brothers, but remain monogamous otherwise. In dunnocks (Prunella modularis) a female's range size determines the mating system of her group (Davies and Lundberg 1984). Finally, Craig (1984) suggested that in pukekos (Porphyrio porphyrio) larger groups have a great advantage in territory defense, and that for this reason a male would often benefit from accepting another male into his group. In addition, once one group did this, its neighbors would be forced to do the same, or risk losing their territories. Both cooperatively polyandrous groups and monogamous groups occur in a wild population of saddle-back tamarins (Saguinus fuscicollis) in Peru's Manu National Park (Terborgh and Goldizen 1985). In this study I attempted to determine the proximate causes of this population's variable mating system.

The coexistence of monogamous groups and cooperatively polyandrous groups in the same tamarin population presented an ideal situation for study of the proximate factors that determine the 
mating system of particular groups. Monogamous groups are defined here as those in which only one adult of each sex is reproductively active during a particular breeding season, with the pair cooperating in the rearing of their young. Data gathered on this S. fuscicollis population from 1979 through 1983 suggested that for the following reasons its variable mating system could not have the same proximate causes as any of the birds described above. (1) At least some polyandrous males in S. fuscicollis were almost certainly not closely related (Terborgh and Goldizen 1985), and males rarely had brothers with whom they could have been polyandrous. (2) Because groups always travel together, territory size would not affect a male's ability to control access to his female, as it does in dunnocks (Davies and Lundberg 1984). (3) Territory boundaries were remarkably stable between years, despite large changes in the relative sizes of neighboring groups.

The early work on this population suggested the alternative hypothesis that the mating system of a saddle-back tamarin group is determined primarily by the number of nonreproductive helpers present in the group (Goldizen and Terborgh 1986). In tamarins, all group members greater than $1 \frac{1}{2}$ years of age provide extensive infant care (including infant-carrying, feeding of fruits and insects to infants and juveniles, and grooming) (reviewed by Sussman and Kinzey 1984; Goldizen, in press; Snowdon and Soini, in press). Individuals which help to care for infants who are not their own offspring are called "helpers" (Skutch 1935; Brown 1978; Emlen 1984).

To test this hypothesis, several assumptions were examined. These are: (1) that helpers provide reliable and predictable care of infants, (2) that a lone pair without helpers would have a very reduced probability of raising twin young (over $80 \%$ of tamarin litters consist of twins), and (3) that polyandrous males do not know which of them actually fathered the female's young, and thus, that both males care for her subsequent infants because of their possible genetic relatedness to them. The hypothesis predicts that: (1) a pair with at least one nonreproductive helper over one and one-half years old could mate monogamously and have a good chance of successfully rearing twin infants, and (2) that both members of a lone pair without helpers would benefit from allowing a second male to join them and mate polyandrously, in exchange for the second male's help with the subsequent infants (Goldizen and Terborgh 1986).

Females are expected to benefit from polyandry more than males, because a polyandrous male's chances of paternity are less than those of a monogamous male. Yet, despite this sexual inequality in potential benefits, a male could still benefit from being polyandrous, either if he had a low probability of breeding as a monogamous male, or if his chances of successfully raising young as a monogamous male were sufficiently less than they would be if he were polyandrous.

Since the study of this $S$. fuscicollis population began in 1979, six years of data have been collected on the compositions of the groups living in four to six territories, and several of these groups have been studied intensively. This paper presents detailed behavioral data gathered on two of these groups during a fourteen month study (February 1984-March 1985) and combines this with longterm group composition data to test the hypothesis presented above.

\section{Methods}

Study animals

Tamarins and marmosets belong to the New World primate family Callitrichidae. Callitrichids range in weight from 100 to 800 grams, with S.fuscicollis adults weighing 350 to 400 grams (Hershkovitz 1977). They are omnivorous and usually live in defended territories of up to one square kilometer (reviewed by Sussman and Kinzey 1984; Goldizen, in press; Snowdon and Soini, in press). The high frequency of twinning and the participation in infant care of all group members and especially adult males differentiate callitrichids from other anthropoid primates (Sussman and Kinzey 1984; Goldizen, in press; Snowdon and Soini, in press).

\section{Study site}

This study was carried out at the Cocha Cashu Biological Station within the Manu National Park in the Department of Madre de Dios in southeastern Peru $\left(11^{\circ} 55^{\prime} \mathrm{S}, 77^{\circ} 18^{\prime} \mathrm{W}\right.$, elevation approximately $400 \mathrm{~m}$.). The vegetation is moist tropical forest. More details on the study site are presented in Terborgh (1983).

\section{Capturing and marking of tamarins}

All of the S. fuscicollis in four territories $(\mathrm{H}, \mathrm{S}, \mathrm{SW}, \mathrm{SE})$ were captured and marked in 1979, and those in three more territories $(\mathrm{R}, \mathrm{N}, \mathrm{W})$ were first marked in 1980, 1982 and 1984 respectively. During the six years of the study, 61 saddle-back tamarins have been marked in these seven territories. After the initial captures the groups in all but one of the seven territories were caught at least once each year through 1984 to mark all new young or immigrant individuals. Capturing and marking methods are described in Terborgh and Goldizen (1985).

\section{Group censuses}

During the six years of the study, most of the marked groups were censused at least once per month during the periods when researchers were at the study site (September-November 1979, August-November 1980, April-September 1981, June-August 1982, June-August 1983, and February 1984-March 1985). In- 
dividuals were called infants until weaning (at about three months), then juveniles up to one year of age, subadults between one and two years, and adults thereafter.

\section{Collection of behavioral data}

From 1979 through 1983 habituated groups in the S and SW territories were followed for over 1,100 hours (Terborgh and Goldizen 1985). During 1984, 236 hours of focal animal samples (Altmann 1974) were collected on the SW territory group during the following periods: 1-16 May, 14 June-1 July, 29 September-11 October, and 15-28 December. The numbers of half-hour focal samples collected on each adult during each of these periods were 39 to 40,29 to 31,30 to 31 , and 12 to 16 , respectively. During foca sampling, an individual was observed for thirty minutes. The focal animal's activity and the identity of its nearest neighbor were sampled instantaneously every two minutes. At the end of the thirty minutes, the focal individual was changed. Every day, the group members were sampled in a particular order, and this order was changed daily. During the first and second study periods, only the three adults were sampled; thus, a particular animal was sampled at 90 -min intervals. During the other two study periods, all five individuals were sampled.

The activity budgets presented below are divided into time spent feeding, traveling and resting. These activities are defined as follows for the remainder of this paper. "Feeding" was recorded whenever an individual ate fruit, nectar, plant exudate, or insect, or handled fruit or substrate in search of insects. "Traveling" was recorded whenever the focal animal was locomoting. "Resting" was recorded when the individual was grooming, being groomed, playing, or whenever it was motionless and not engaged in any of the other activities listed above. Thus, even very brief pauses in other activities were scored as resting if they occurred at the time of an instantaneous sample. Grooming was included in this category because it usually occurred during general rest sessions. Only juveniles were observed playing during focal samples.

Beginning one or two days after infants were born in the SW and S troops, a form of scan sampling was done on each of these groups for two or three days approximately every two weeks. This was continued until the SW troop infants were six weeks old and the S troop infants four weeks old. During scan samples, the identity and activity of the infant-carrier (or carriers) were determined instantaneously at five-minute intervals throughout the day, whenever the tamarins were in sight. The same activity categories were used as for the focal sampling. Only scan samples in which both infants were visible are included in this paper. The numbers of scan samples taken on the SW group during the four sampling periods were 162,178 , 97 and 175, respectively; and on the $S$ group, the numbers of samples taken were 98,142 , and 122, respectively. Scan and focal sampling were not done simultaneously.

For both the SW and S troops, a number of behaviors were recorded whenever they were observed (ad-libitum data) (Altmann 1974). This was done for behaviors that were not common enough to sample systematically, such as copulations, aggression, donation of fruits or insects to infants, alarm calls, and attacks by predators. $S$. fuscicollis copulations last a few seconds, with the male thrusting about ten times. At the end of a copulation the female usually turns around to look at the male and he generally flicks his tongue in and out.

\section{Analysis of behavioral data}

For some analyses, data from each half-hour focal animal sample (including up to fifteen instantaneous samples) were used as one independent sample. For example, activity budgets were calculated from focal samples by calculating the proportions of the activity data points during each half hour that belonged to each of the three activity classes. Each of these proportions was then used as one sample for statistical analysis. For other types of analyses, all of the two-minute instantaneous focal samples for a given individual were combined for each day of data, such that each day provided one independent sample. The five-minute scan samples were also analyzed in two ways. Each five-minute data point was considered to be a sample only for descriptive statistics. Because these five-minute samples were not really independent, all of the five-minute samples were lumped for each day whenever possible, and each day's data were then considered to be one independent sample. Statistical tests follow Sokal and Rohlf (1981).

\section{Results}

Compositions and mating patterns

of the two main study groups

1. Composition and mating patterns of the $S$ troop. In February 1985 the $S$ troop contained one adult male (S-M1), three adult females (S-F1, S-F2 and S-F3), two subadults (S-SM and S-SF), and two infants. S-F1 was the mother of all but S-M1; S-F2 was born in late 1981, S-F3 in late 1982, the subadults in late 1983, and the infants between 15 and 17 February 1985. These last infants were SF1's fifth set of twins. S-M1 had immigrated into the group between September 1983 and February 1984 and thus could only have fathered the last set of twins. This group was polygynous in its mating pattern in 1984; both S-F1 and her daughter, $\mathrm{S}-\mathrm{F} 2$, conceived. S-F2 was seen in an advanced state of pregnancy in early January 1985, but was never seen with infants; thus, it is thought that her babies were born during the first or second week of January and died soon after birth. S-F1's twins, born in February, survived to at least three months of age. Therefore, though this group was polygynous in terms of mating, only one set of offspring survived, and the parental care patterns of this group are assumed to be representative of those of monogamous groups.

2. Composition of $S W$ troop. The second group (SW troop) contained the following individuals in February 1985: two adult males (SW-M1 and SWM2), one adult female (SW-F), two subadult males born in January or February 1984 (SW-SM1 and SW-SM2) and two juvenile females born on 3 or 4 November 1984. SW-F had been the reproductive female in the same territory since at least 1979 and had had three or more sets of twins. Between August 1983 and January 1984 the rest of her previous group (her mate and two of her older off- 
Table 1. Numbers of copulations by each of the SW troop males with the SW troop female. The significance of differences between the two males was tested with G-tests of goodness of fit using Williams' correction. From 3 May to 1 July the female was in late lactation, then early pregnancy; from 9 September to 16 October she was in advanced pregnancy; and the 8 November to 23 February period included lactation and post-lactation

\begin{tabular}{lllll}
\hline Time period & \multicolumn{4}{c}{ Numbers of copulations by males } \\
\cline { 2 - 5 } & SW-M1 & SW-M2 & $\mathrm{G}_{\text {adj }}$ & Probability \\
\hline $\begin{array}{l}\text { 3 May 1984- } \\
\text { 1 July 1984 } \\
\text { 9 Sept. 1984 } \\
\text { 16 Oct. 1984 }\end{array}$ & 14 & 10 & 0.66 & $P>0.2$ \\
$\begin{array}{l}\text { 8 Nov. 1984- } \\
\text { 23 Feb. 1985 }\end{array}$ & 4 & 16 & 3.54 & $0.1>P>0.05$ \\
\hline Totals & 5 & $\begin{array}{l}\text { Sample sizes too } \\
\text { small for statistical } \\
\text { comparison }\end{array}$ \\
\hline
\end{tabular}

spring) all emigrated or died, and SW-M1 and SW$\mathrm{M} 2$ moved into her territory. It is thus not known whether her past mate or SW-M1 or SW-M2 fathered the infants born in early 1984. It is also not known whether SW-M1 and SW-M2 were related to each other, because they immigrated from outside the marked population.

3. Evidence that the $S W$ troop was polyandrous. The SW troop female was seen copulating with the group's two males 56 times between May 1984 and February 1985. These copulations occurred when she was pregnant, lactating, and possibly, neither pregnant nor lactating. There was no significant difference in the total number of times SW-M1 and SW-M2 each mated with the female, and this was also true during each of the sampling periods during the year (Table 1).

Data on the social behavior of the two males also showed that they had similar relationships with the female. For each half-hour focal sample on the female $(n=140)$, I determined whether SWM1 or SW-M2 had been the female's nearest neighbor during more of the two-minute instantaneous samples. The only time of the year when there was a significant difference in how often each male was the female's nearest neighbor was during September 14-18, when SW-M2 was her neighbor more often than was SW-M1 (Table 2). During this five day period during the female's pregnancy, both males were extremely interested in the female and each appeared to be trying to guard her from the other male. Similar incidents were observed in other years (Terborgh and Goldizen 1985). When the data from all of the sample periods (except September 14-18) were pooled, there was no significant difference in which male was the female's nearest neighbor (Table 2).

\section{Testing the assumption that helpers provide substantial infant care}

1. General patterns of infant-carrying. Tamarin infants were carried by older group members until they were about three months old. Towards the end of this period they were carried only occasionally, for example during general alarms or when the infants were unable to traverse a certain area. During their first three weeks, infants were on the back of an older group member all of the time; by six weeks of age they were independent during 41.5 percent of the scan samples, and by two months of age they frequently traveled short distances themselves.

Twins were sometimes carried simultaneously by the same individual and at other times were carried separately by two individuals. The percentages of time during which twin infants were carried

Table 2. Comparison of the number of times the SW troop's SW-M1 and SW-M2 were more often the nearest neighbor of the adult female during half-hour focal samples. The significance of differences between the males was tested with two-tailed sign tests. $\mathrm{NS}=P>0.05$

\begin{tabular}{lllll}
\hline Sample dates & $\begin{array}{l}\text { Number of samples } \\
\text { when SW-M1 more } \\
\text { often nearest } \\
\text { neighbor of female }\end{array}$ & $\begin{array}{l}\text { Number of samples } \\
\text { when SW-M2 more } \\
\text { often nearest } \\
\text { neighbor of female }\end{array}$ & $\begin{array}{l}\text { Number of samples } \\
\text { when neither male } \\
\text { more often nearest } \\
\text { neighbor }\end{array}$ & $\begin{array}{l}\text { Chi-square } \\
\text { value }\end{array}$ \\
\hline 1 May 1984-16 May 1984 & 12 & 19 & 8 & NS \\
14 June 1984-1 July 1984 & 10 & 10 & 9 & NS \\
14 Sept. 1984-18 Sept. 1984 & 3 & 24 & 1 & $P<0.01$ \\
20 Sept. 1984-11 Oct. 1984 & 14 & 14 & 2 & NS \\
15 Dec. 1984-28 Dec. 1984 & 5 & 4 & 5 & NS \\
For all data except 14-18 Sept. & 41 & 47 & 24 & NS \\
\hline
\end{tabular}




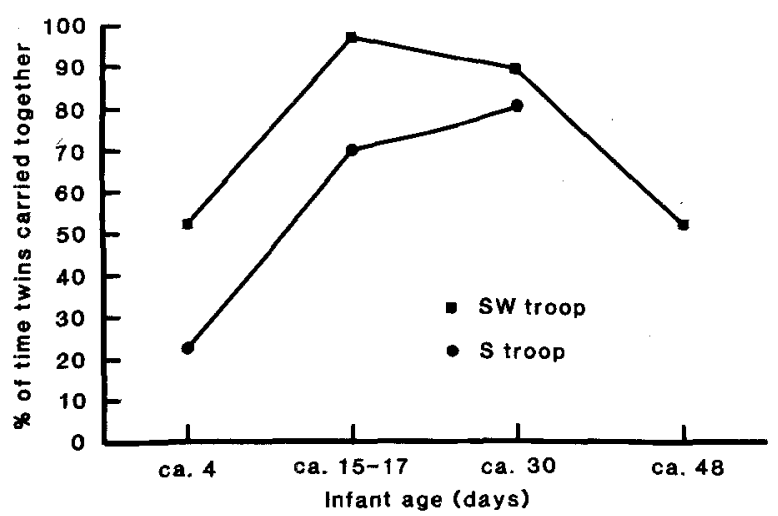

Fig. 1. Percentages of time that SW and $S$ troop infants were carried together on one individual as a function of infant age

together versus apart changed dramatically within two week intervals (Fig. 1). During the first sampling period, which occurred when the infants were only days old, they were carried together only half of the time (SW group) or less (S group). Then in both groups twins were carried together the majority of the time when they were two weeks to a month old, after which the percent of time that they were carried separately increased again.

2. Division of infant-carrying by $S$ and $S W$ group members. Adult male $S$. fuscicollis carried infants about twice as often as did the infants' mothers, in both the S and SW troops (Table 3). Both SW troop males carried one or two infants significantly more often than did the infants' mother (Wilcoxon signed-rank tests, two-tailed, $P<0.05$ for all comparisons). The two males did not differ significantly in infant-carrying. The number of scan samples done on the $S$ troop $(n=362)$ was smaller than for the SW troop $(n=612)$, because the $S$ troop was more difficult to observe. The difference in infant-carrying frequency between the reproductive male and female in the $S$ troop was in the same direction as in the SW group, but this difference was not statistically significant (Wilcoxon signed-rank test, two-tailed, $P>0.10$ ).

The amount of infant-carrying done by nonreproductive helpers varied, depending in part on the ages of the helpers. In the $S$ troop, the threeyear old S-F2 did more carrying than did the twoyear old S-F3, who in turn did more than did either of the one-year olds (S-SM and S-SF) (Table 3). The two SW troop juveniles were each seen carrying their siblings on only one occasion.

The proportions of the total infant-carrying done by each group member during the infants' first month were calculated from data on the average number of infants carried by each individual
Table 3. Percentages of instantaneous scan samples during which each S and SW group member carried none, one or two infants. Data were collected during the first seven weeks of the SW group infants' lives and during the first four weeks of life of the $S$ troop infants. These results were calculated by averaging all of the 5-min scan samples for each day of sampling, and then averaging together the percentages calculated for each of the twelve sample days

\begin{tabular}{llll}
\hline Individual & $\begin{array}{l}\text { Percentage } \\
\text { of time } \\
\text { carried } \\
\text { 0 infants }\end{array}$ & $\begin{array}{l}\text { Percentage } \\
\text { of time } \\
\text { carried } \\
1 \text { infant }\end{array}$ & $\begin{array}{l}\text { Percentage } \\
\text { of time } \\
\text { carried } \\
2 \text { infants }\end{array}$ \\
\hline $\begin{array}{l}\text { SW-M1 } \\
\text { (adult male) }\end{array}$ & 49.9 & 17.4 & 32.7 \\
$\begin{array}{l}\text { SW-M2 } \\
\text { (adult male) }\end{array}$ & 51.3 & 19.3 & 29.4 \\
$\begin{array}{l}\text { SW-F } \\
\text { (mother) }\end{array}$ & 80.8 & 6.6 & 13.4 \\
$\begin{array}{l}\text { S-M1 } \\
\text { (adult male) }\end{array}$ & 52.9 & 19.8 & 27.3 \\
$\begin{array}{l}\text { S-F1 } \\
\text { (mother) }\end{array}$ & 67.7 & 21.6 & 10.7 \\
$\begin{array}{l}\text { S-F2 } \\
\text { (adult female) }\end{array}$ & 66.2 & 21.3 & 12.5 \\
$\begin{array}{l}\text { S-F3 } \\
\text { (adult female) }\end{array}$ & 80.0 & 9.4 & 10.6 \\
$\begin{array}{l}\text { S-SM } \\
\text { (sub. male) }\end{array}$ & 96.8 & 2.6 & 0.6 \\
$\begin{array}{l}\text { S-SF } \\
\text { (sub. female) }\end{array}$ & 99.0 & 1.0 & 0.0 \\
\hline
\end{tabular}

Table 4. Proportions of the SW and S groups' infant-carrying done by each of the groups' individuals during the first month of the infants' lives. These values were calculated by averaging the mean number of infants carried by each individual during the first three sampling periods on each set of twins. The three sampling periods were weighted equally in calculating these mean values

\begin{tabular}{llll}
\hline SW troop & & & S troop \\
\cline { 1 - 1 } Individual & $\begin{array}{l}\text { Percentage } \\
\text { of group's } \\
\text { total carrying }\end{array}$ & Individual & $\begin{array}{l}\text { Percentage } \\
\text { of group's } \\
\text { total carrying }\end{array}$ \\
\hline SW-M1 & 43.4 & Adult male & 37.1 \\
SW-M2 & 36.7 & S-F1 (mother) & 22.8 \\
Adult female & 19.9 & S-F2 & 24.4 \\
(mother) & & S-F3 & 12.2 \\
& & Subadult male & 3.0 \\
& & Subadult female & 0.5 \\
\hline
\end{tabular}

during scan samples (Table 4). In this way the two groups could be compared at identical periods in the infants' lives. In both groups each adult male did about $40 \%$ of the total carrying, whereas the two mothers did about $20 \%$. The percentage of the carrying done by the second male in the SW 

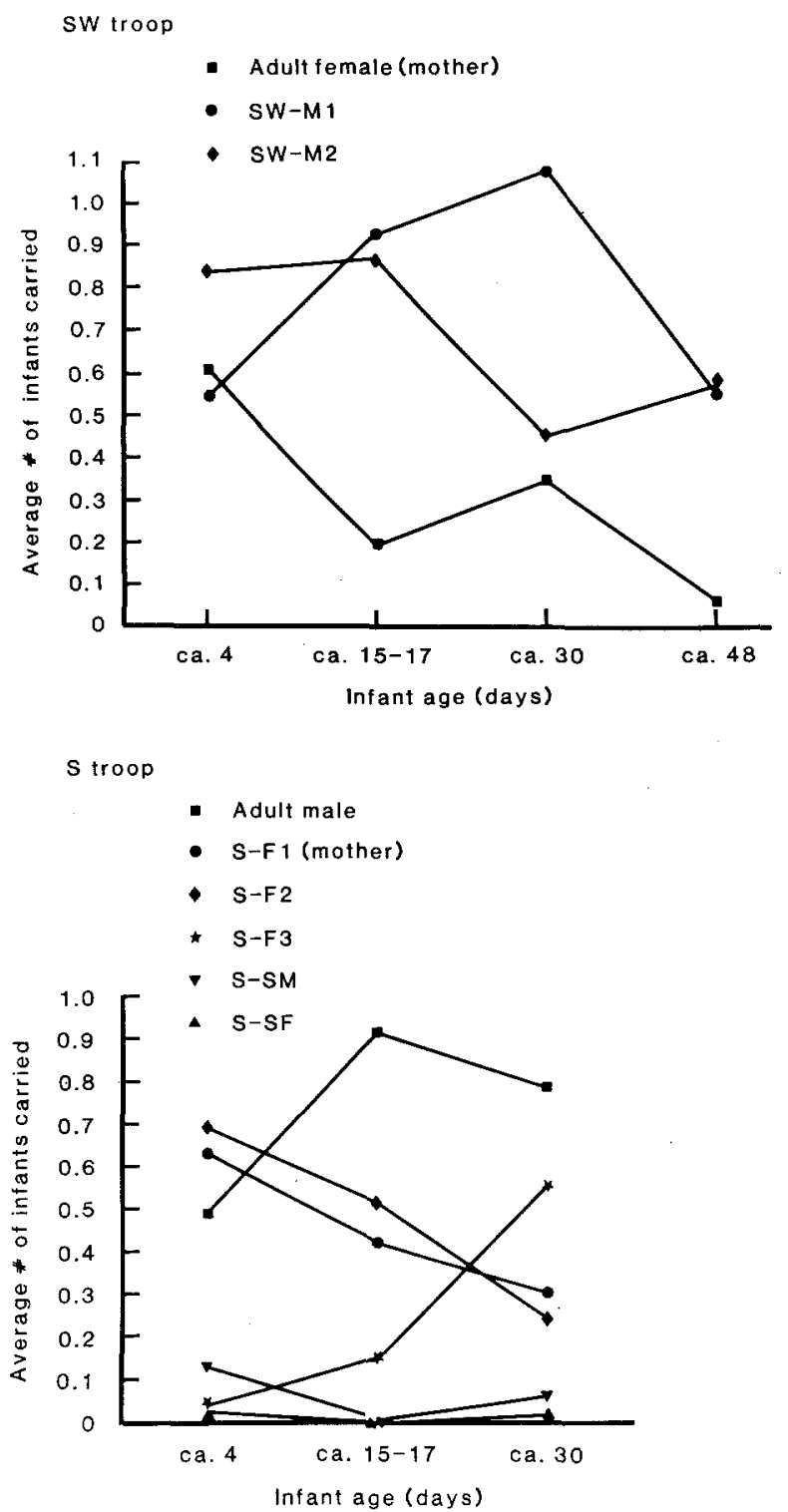

Fig. 2. The average number of infants carried by each group member versus infant age in SW troop (above) and S troop (below). These results were calculated by averaging the number of infants carried during each 5-min sample. The total number of infants carried began dropping at one month of age as the infants started occasionally moving around independently

group was close to the amount of carrying done by the four helpers in the $\mathrm{S}$ group.

\section{Changes in infant-carrying patterns with infant} age. The average number of infants carried by each member of the S and SW groups changed over time during the first four to seven weeks of the infants' lives (Fig. 2). Most notable is the general decline in carrying by the mothers in each group and by S-F3. This decrease appeared to be partially compensated for by an increase in carrying by the
$\mathrm{S}$ troop's adult male and by SW-M1 in the SW group. Carrying by the two-year old female (S-F3) increased dramatically throughout the first month; she did virtually no carrying the first few days, but carried more than did either S-F1 or S-F2 by the end of the month. The group's adults appeared not to allow S-F3 to handle the infants at first, and only gradually let her carry more and more often. In both groups, the yearlings did very little carrying at any time.

\section{Testing the assumption that lone pairs would have difficulty raising young}

1. Reproductive success of monogamous pairs without helpers. Groups consisting of lone monogamous pairs (with no helpers) almost never occurred in the study population. The one lone pair that did occur (out of 33 group-years) was part of a two male-one female trio when the female's infants were conceived. One of the adult males disappeared after the female conceived but at least three months before the birth of the infants. The remaining pair did manage to raise one infant to at least six months of age, but the other infant disappeared within a few weeks after birth.

Because lone pairs so rarely attempt to raise young, there are not enough data available to directly assess their ability to do so. Therefore, I first present data on the energetic costs of lactation and infant-carrying, and then use these to calculate the approximate energetic consequences to an adult pair of attempting to raise infants without help.

2. General activity budgets of $S W$ troop members. The comparison of the mean activity budgets of the three adults shows that the adult female spent $8-12 \%$ more time feeding than did the two adult males (Mann-Whitney $U$-tests, two-tailed, $P<$ 0.005 for both comparisons), and $10-13 \%$ less time resting, whereas all three individuals spent approximately equal time (14 to $16 \%$ ) in travel. The two males did not differ significantly in the amounts of time that they spent feeding (Mann-Whitney Utest, two-tailed, $P=0.3424$ ) (Fig. 3).

3. Costs of lactation. The individual activity budgets did not remain constant throughout the year. The SW group female was lactating during the May and December sample periods, in early pregnancy in June, and in late pregnancy during September and October. She spent significantly more time feeding during the two sample periods when 

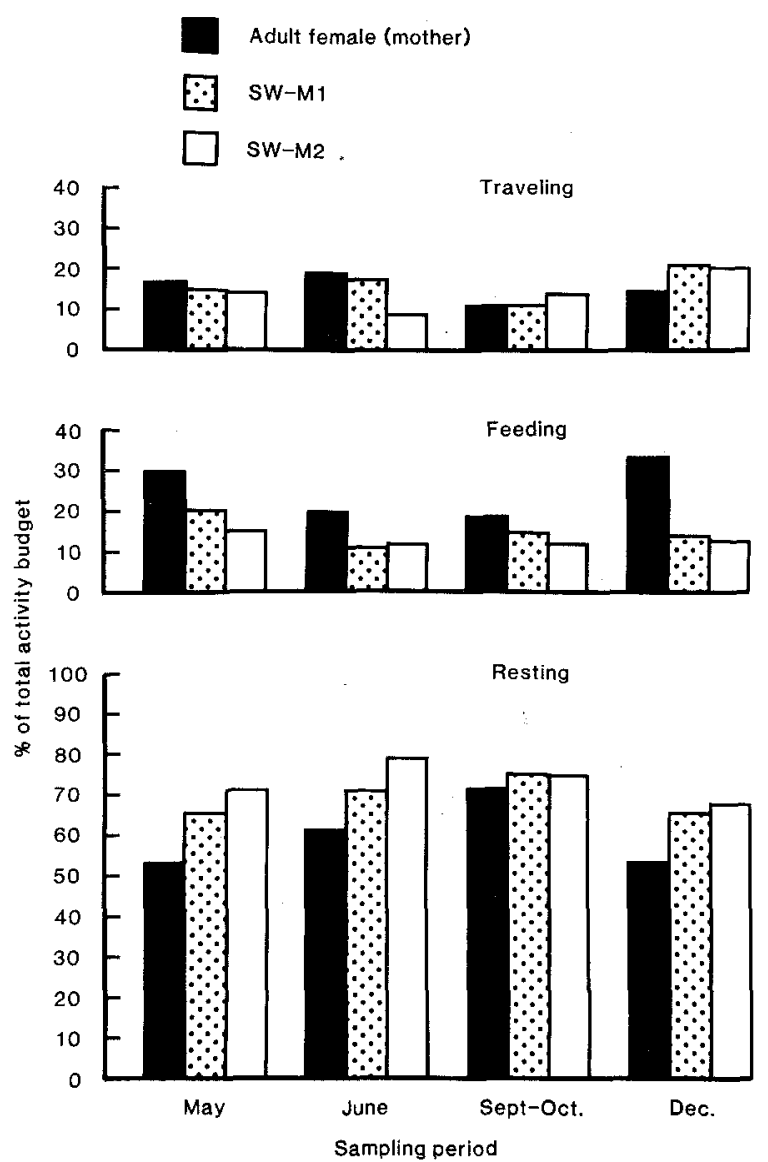

Fig. 3. Activity budgets of SW troop adults during the four sampling periods. The percentages of time individuals engaged in three different general activities (Rest, Feed, Travel) were calculated from focal sampling data. These activity classes are defined in the text. SW-M1 and SW-M2 were the two SW troop adult males

she was lactating than she did during the samples when she was pregnant (Mann-Whitney $U$, twotailed, $P=0.0024$ ). Neither of the two adult males spent significantly different amounts of time feeding during these same sample periods, although the difference was almost significant for SW-M1 (Mann-Whitney $U$, two-tailed tests, $P=0.0552$ for SW-M1 and $P=0.2932$ for SW-M2). The female fed significantly more than did the two males during the May, June and December samples (MannWhitney $U$-tests, two-tailed, $P=0.0008,0.0254$ and 0.0062 , respectively), but not during the September-October sample (Mann-Whitney $U$, twotailed, $P=0.2838$ ) (Fig. 3).

4. Costs of infant-carrying. The adult's activities did not appear to be affected by whether they were carrying two infants at once or one. When they carried only one infant they spent $87.2 \%$ of their time resting, $6.4 \%$ feeding and $6.4 \%$ traveling $(n=$
203 scan samples). When carrying two infants they rested $80.5 \%$ of the time, fed $5.2 \%$ and traveled $14.3 \%$ ( $n=328$ scan samples). These percentages were calculated by averaging data from all scan samples collected during the infants' first six weeks. There were not sufficient data to do this calculation using each day's observations as one sample, because of the changes in the frequencies of carrying one versus two infants (Fig. 1). Thus, the activity budgets while carrying one or two infants cannot be compared statistically, but they appear to be sufficiently similar to justify lumping all infant-carrying together (whether the carrier had one or two infants on its back) for the rest of this paper.

All three SW troop adults rested more, fed less and traveled less while carrying infants than while not carrying infants (Fig. 4). The differences in time spent feeding while carrying compared with not carrying were statistically significant for SW-F and SW-M1 (Wilcoxon 2-sample tests, two-tailed, $P<0.05$ and $P=0.01$, respectively), but not significant for SW-M2 $(P=0.1)$.

Comparisons of the activity budgets of the three adults while carrying infants show that the female's activities were more affected by infantcarrying than were the males' activities (Fig. 4). Considering activities of the adults only when they carried infants, the female rested more and fed and traveled less than did either male.

5. Modeling a lone pair's chances of reproductive success. In this section I use the results just presented on the division of infant-carrying among group members and the costs of lactation and infant-carrying (measured in terms of feeding time) to estimate the amount of time the male and female of a lone pair with dependent infants would be able to feed. These feeding times are then compared with the level of feeding thought to be necessary.

The average percent of time spent feeding for the two SW troop males during the May, June and September focal sampling periods (when there were no infants in the group) was $14.3 \%$ (from Fig. 3) and is called the level of feeding necessary for the maintenance of an adult. This assumes that the amount of time that tamarins need to spend feeding is relatively invariant at different times of the year. The amount of time that the males spent feeding did not vary greatly at different times of the year in this study (Fig. 3), but see Terborgh (1983) for a different opinion. These calculations must be considered to be approximations until this assumption is better tested. 

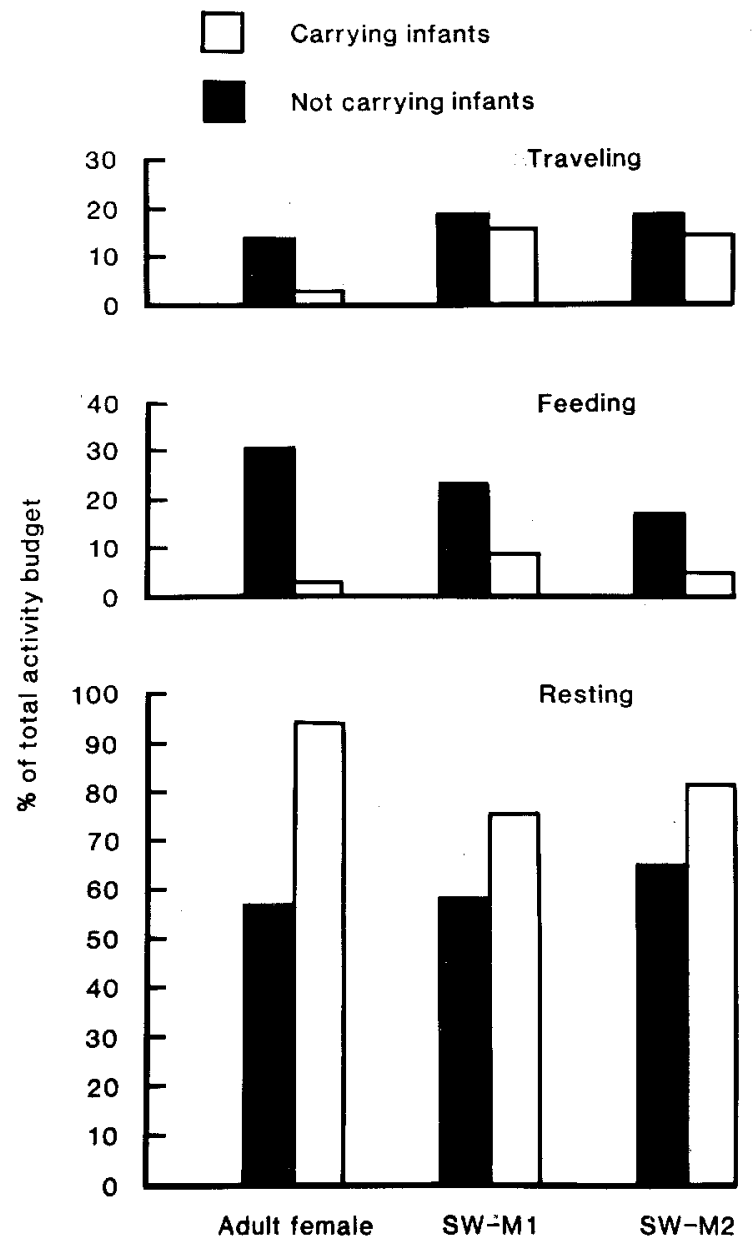

Fig. 4. Comparisons of the amounts of time each SW troop adult spent engaging in each general activity class while carrying infants versus while not carrying infants. Activity data while carrying infants were calculated from scan sampling data using each day's data as one independent sample. Scan samples were collected during the infants' first seven weeks of life. Samples were used whether the carrier had one or two infants. Activity data while not carrying infants was calculated using data collected during focal samples when the infants were six to eight weeks old. Each day's data were averaged to produce the percentages of time spent in each activity per day. Five days of focal sampling data were used for the adult female and SW-M1, and six days were used for SW-M2

The female's lowest feeding levels measured were $19.9 \%$ and $18.9 \%$ (during the June and September-October samples, respectively) (Fig. 3), perhaps because she was pregnant during both of these samples. Near the end of the female's period of lactation (when she was no longer carrying infants) for the set of infants born in February 1984, the female spent $29.8 \%$ of her time feeding. This is consistent with the results of the Kirkwood and Underwood (1984) study showing that lactating female cotton-top tamarins (Saguinus oedipus) approximately double their normal energy intakes.
The percentage of time each of the adults spent feeding during the infant-carrying period was calculated as follows:

$\% \mathrm{~F}=\left(\% \mathrm{~F}_{\mathrm{NI}}\right)\left(\% \mathrm{~T}_{\mathrm{NI}}\right)+\left(\% \mathrm{~F}_{\mathrm{I}}\right)\left(\% \mathrm{~T}_{\mathrm{I}}\right)$

$\% \mathrm{~F}=$ average percent of time spent feeding,

$\% \mathrm{~F}_{\mathrm{NI}}=$ percent of time spent feeding while not carrying infants,

$\% \mathrm{~F}_{\mathrm{I}}=$ percent of time spent feeding while carrying infants,

$\% \mathrm{~T}_{\mathrm{NI}}=$ percent of time spent not carrying infants, $\% \mathrm{~T}_{\mathrm{I}}=$ percent of time spent carrying infants.

These values of $\% \mathrm{~F}_{\mathrm{NI}}$ and $\% \mathrm{~F}_{\mathrm{I}}$ for each individual were taken from Fig. 4. Because carrying one infant appeared to have the same effect on feeding time as carrying two, for these calculations I used the percentage of time that each SW group adult carried at least one infant (derived from Table 3). According to these calculations, SW-M1 spent $15.8 \%$ of his time feeding during the infantcarrying period, SW-M2 spent $10.7 \%$ and the female spent $24.8 \%$. At least in this trio, the adult males appeared to be able to feed at a level close to that necessary for maintenance (although SWM2's feeding level was somewhat low). The female did not feed quite as much as she was assumed to require during lactation $(29.8 \%)$ but as for SWM2 the difference was not great.

The average values for $\% \mathrm{~F}_{\mathrm{NI}}$ and $\% \mathrm{~F}_{\mathrm{I}}$ from the two SW troop males and the values from the SW troop adult female (from Fig. 4) were then used to calculate (with the same formula) what might happen to a lone pair trying to raise infants. These calculations suggest that if the pair split infant-carrying equally, the male would spend $13.1 \%$ of his time feeding and the female $16.5 \%$. In this situation it appears that the male would still be able to feed at the level necessary for maintenance, but the female would not even approximate sufficient feeding time to meet the energetic demands of lactation. If the male of the lone pair did twice as much carrying as did the female, he would then spend $10.9 \%$ of his time feeding, while she would spend $21.1 \%$ of her time doing so. Even in this situation the female would be feeding much less than the 28 or $29 \%$ she is assumed to require during lactation. These calculations are discussed further below.

\section{Discussion}

The hypothesis that the mating system of an S. fuscicollis group is determined primarily by the number of nonreproductive helpers (usually older 
offspring) in the group makes two predictions. First, a pair with helpers would have sufficient help with infant care and should mate monogamously, and second, both members of a pair without helpers might benefit from becoming polyandrous, although the female would presumably benefit more than would the male. Three lines of evidence support this hypothesis: (1) no monogamous pairs without helpers ever attempted an entire breeding cycle (starting from conception) alone during the 33 group-years of the study (groups breed once per year at Cocha Cashu); (2) older offspring contribute substantially to infant-carrying; and (3) the distribution and costs of infant care suggest that lone pairs would rarely be able to raise twins.

\section{Contributions of non-reproductive helpers}

Non-reproductive $S$. fuscicollis helpers do as much as $25 \%$ of the carrying of the infants in their groups (Table 4 and Fig. 2; Terborgh and Goldizen 1985). All of the nonreproductive helpers in the S and SW groups in 1984 were known to be at least maternal half-siblings of the infants they helped raise. Captive studies of callitrichid species of three genera (Callithrix, Leontopithecus and $\mathrm{Sa}$ guinus) have also documented substantial amounts of infant-carrying by siblings (e.g. Epple 1978; Hoage 1978; Ingram 1978). In the wild, infantcarrying by one-year old individuals seems less predictable than that by two- or three-year old nonreproductive individuals still in their natal groups, though yearlings are capable of substantial infantcarrying (Terborgh and Goldizen 1985). That twoyear olds generally do more carrying than yearlings accords with the fact that two-year old tamarins are of adult body size and weight, whereas yearlings are still much smaller.

Non-reproductive helpers also donate food items to infants and juveniles. Terborgh and Goldizen (1985) and Goldizen (in press) discuss the benefits that non-reproductive tamarins may gain from helping to raise their full or half-siblings. These are similar to the benefits postulated for "helpers at the nest" in birds (reviewed by Brown 1978; Emlen 1982a, 1982b, 1984).

\section{Costs of infant care}

The costs of infant-carrying are substantial: both males and females spent at least $12.3 \%$ less time feeding and $16.5 \%$ more time resting when carrying infants than when not carrying (Fig. 4). Infantcarrying could be directly incompatible with feeding because of the energetic costs or discomfort caused by transporting infants. Infant-carrying may also be indirectly incompatible with feeding because of the vulnerability of small infants to predators or to falling from the backs of moving adults. The males did not travel less when carrying infants than when not carrying (Fig. 4). This is as expected since $S$.fuscicollis group members travel together all day and never leave infants "parked".

During lactation females cannot afford to do as much carrying as can males. The SW troop female spent about one and one-half times as much time feeding during lactation as she did during pregnancy. Lactating female $S$. fuscicollis did only about $20 \%$ of the carrying of a set of infants, while adult males did about $40 \%$ (Table 4 ; see also Terborgh and Goldizen 1985).

These data on the costs of lactation and infantcarrying were used to estimate the costs a lone pair would incur in raising a set of twins without other help. Although these calculations are only approximate, they suggest that a lone pair might not be able to feed sufficiently to raise twin infants. Furthermore, the calculations made above for the lone pair assume that twins would always be carried together, which is unrealistic. When the infants are very young, and again after about their sixth week, they are carried separately $50 \%$ or more of the time (Fig. 1). Observations of few-dayold infants suggest that they are not yet adept at clinging and that when twins are carried together, the one closer to the adult's tail has a harder time clinging, perhaps explaining why they are often carried separately at this age. The later increase in carrying the infants separately is probably due to the increasing weight of the infants. Thus, if the infants of a lone pair were frequently carried separately, the percentages of time spent carrying infants would increase for both adults, reducing their average percentages of time spent feeding still further.

Predation might also reduce the reproductive success of lone pairs. Tamarins appear extremely vulnerable to predators; at this study site they are known to have been caught by ornate hawk-eagles (Spizaetus ornatus) (J. Terborgh and C. Janson, personal communication) and by ocelots (Felis pardalis) (L. Emmons, pers. comm.). Predation attempts by raptors occur about once per week per group (Goldizen, unpubl.). Because of their small size, young tamarins are presumably vulnerable to attack by more raptor species than are adults. The mortality rate during the first year of life in the tamarin study population is between 33 and $50 \%$ (Goldizen, unpubl.). It seems very likely that for 
tamarins the chance that a predator would be detected would increase with group size, as has been suggested for long-tailed macaques (Macaca fascicularis) (van Schaik et al. 1983) and many other animals (reviewed by Bertram 1978). Thus, the effects of predation are likely to support the assumption that lone pairs would have difficulty raising young.

The hypothesis that a group's mating system is determined by the number of helpers it has predicts that a pair without at least one helper $1^{1 / 2}$ years of age should form a polyandrous trio. In this study, only six groups (in 33 group-years) contained no offspring more than one year old during the season when conceptions occurred. As expected, five of these six groups contained two adult males and one female. Although matings were seen in only one of these groups (SW troop 1984), none of the males were close relatives of the females with which they lived, and thus, it seems probable that all five groups were polyandrous. The sixth group contained only one adult male, one female, and one juvenile. It is not known whether the group produced offspring that year (Goldizen, unpublished observations).

One of the assumptions of this hypothesis is that polyandrous males do not know which of them actually fathered their female's infants. This assumption was not directly tested in this study, but would seem to be supported by the fact that the SW troop males split both copulations with the female and the care of her young quite equitably (Tables 1, 3, and 4). Presumably polyandrous males would, on average, increase their lifetime reproductive success by caring for infants who could be theirs. The almost complete lack of aggression between polyandrous male tamarins (Goldizen, in prep.), the apparent equality in the social relationships of at least some pairs of polyandrous males (Table 2), and the fact that most of the copulations of either male are not disturbed by the other male (Terborgh and Goldizen 1985) make this assumption seem reasonable. Other cooperatively polyandrous species show a different pattern. For example, polyandrous trios in dunnocks have identifiable alpha and beta males. Davies (1985) argues that alpha males of trios have reduced reproductive success relative to monogamous males and try to keep the beta males from mating with the females.

The evidence presented here suggests that the facultative polyandry found in the study population of $S$. fuscicollis is due to the advantages to breeders of having extra help in raising young, although more data are needed to conclusively test this hypothesis and alternatives. Ultimately, this need for extra help with parental care is linked to the twin litters and large weights of infants at weaning. These two characteristics are common to all genera of the Callitrichidae (Saguinus, Leontopithecus, Callithrix, Cebuella) except Callimico, which is often regarded as being in a separate family (Hershkovitz 1977). Thus, if this hypothesis is correct, other callitrichid species should also have some polyandrous groups. In fact, moustached tamarins (S. mystax) are thought to be facultatively polyandrous (Garber et al. 1984). However, the frequency of polyandry may differ between species or between populations of the same species, if the costs of infant care differ, due, for example, to differences in food availability.

Acknowledgements. I am indebted to John Terborgh for getting me involved with the tamarins originally and for much valuable support throughout the years of this project. I thank F. Cornejo, R. Evans, C. McVay, B. Mitchell, N. Muckenhirn, P. Neyman, T. Porras, M. Reichman, P. Stern and C. Wise for assistance in the field. B. Curry, P.R. Grant, B.A. Hazlett, W. Holmes, M. van Noordwijk, B. Rathke, C. van Schaik, B. Smuts, J. Terborgh, R. Wrangham, and two anonymous reviewers kindly commented on earlier drafts of the manuscript. I thank A.R. Goldizen for assistance and support of all kinds. Permission to use the Cocha Cashu Biological Station was graciously extended by the Direccion General Forestal y de Fauna of the Peruvian Ministry of Agriculture and the staff of the Manu National Park. This work was supported by NSF grants DEB79-04750 and BNS79-15079 to John Terborgh and by the following grants to the author; NSF grant BSR-8311782, Grant \# 4499 from the Wenner-Gren Foundation for Anthropological Research, an Edwin Edwards Scholarship and three Block Grants from the University of Michigan, a Charles Tobach Award from the T.C. Schneirla Research Fund, a Grant-in-Aid of Research from Sigma Xi - the Scientific Research Society, and Grant No. 220 of the Joseph Henry Fund of the National Academy of Sciences.

\section{References}

Altmann J (1974) Observational study of behavior: sampling methods. Behaviour 49:227-267

Bertram BCR (1978) Living in groups: Predators and prey. In: Krebs JR, Davies NB (eds) Behavioural ecology: An evolutionary approach. Sinauer Associates, Sunderland, Massachusetts, p 64-96

Brown JL (1978) Avian communal breeding systems. Ann Rev Ecol Syst 9:123-155

Craig JL (1984) Are communal pukeko caught in the prisoner's dilemma? Behav Ecol Sociobiol 14:147-150

Davies NB (1983) Polyandry, cloaca-pecking and sperm competition in dunnocks. Nature 302:334-336

Davies NB (1985) Cooperation and conflict among dunnocks, Prunella modularis, in a variable mating system. Anim Behav 33:628 648

Davies NB, Lundberg A (1984) Food distribution and a variable mating system in the dunnock, Prunella modularis. J Anim Ecol 53:895-912

Emlen ST (1982a) The evolution of helping. 1. An ecological constraints model. Am Nat 119:29-39

Emlen ST (1982b) The evolution of helping. 2. The role of behavioral conflict. Am Nat 119:40-53 
Emlen ST (1984) Cooperative breeding in birds and mammals. In: Krebs JR, Davies NB (eds) Behavioural ecology: An evolutionary approach 2 nd edn, Sinauer Associates, Sunderland, Massachusetts, pp 305-339

Epple G (1978) Reproductive and social behavior of marmosets with special reference to captive breeding. Prim Med 10:50-62

Faaborg J, deVries T, Patterson CB, Griffin CR (1980) Preliminary observations on the occurrence and evolution of polyandry in the Galapagos hawk (Buteo galapagoensis). Auk 97:581-590

Faaborg J, Patterson CB (1981) The characteristics and occurrence of cooperative polyandry. Ibis $123: 477-484$

Garber PA, Moya L, Malaga C (1984) A preliminary field study of the moustached tamarin monkey (Saguinus mystax) in northeastern Peru: Questions concerned with the evolution of a communal breeding system. Folia Primatol 42:17-32

Goldizen AW (in press) Tamarins and marmosets: Communal care of offspring. In: Smuts BB, Cheney DL, Seyfarth RM, Wrangham RW, Struhsaker TT (eds) Primate Societies. University of Chicago Press, Chicago

Goldizen AW, Terborgh J (1986) Cooperative polyandry and helping behavior in saddle-backed tamarins. In: Lee P, Else JG (eds) Proc Xth Congress of the International Primatological Society: Primate Ecology and Conservation. Cambridge University Press, London, pp 191-198

Hershkovitz P (1977) Living new world monkeys (Platyrrhini), vol 1. University of Chicago Press, Chicago

Hoage RJ (1978) Parental care in Leontopithecus rosalia rosalia: Sex and age differences in carrying behavior and the role of prior experience. In: Kleiman DG (ed) The biology and conservation of the Callitrichidae. Smithsonian Institution Press, Washington DC, pp 293-305

Ingram JC (1978) Parent-infant interactions in the common marmoset (Callithrix jacchus). In: Kleiman DG (ed) The biology and conservation of the Callitrichidae. Smithsonian Institution Press, Washington DC, pp 281-291

Joste N, Ligon JD, Stacey PB (1985) Shared paternity in the acorn woodpecker (Melanerpes formicivorus). Behav Ecol Sociobiol 17:39-41

Kirkwood JK, Underwood SJ (1984) Energy requirements of captive cotton-top tamarins (Saguinus oedipus oedipus). Folia Primatol 42:180-187

Mader WJ (1979) Breeding behavior of a polyandrous trio of Harris' hawks in southern Arizona. Auk 96:776-788

Maynard Smith J, Ridpath MG (1972) Wife sharing in the Tasmanian native hen, Tribonyx mortierii: A case of kin selection? Am Nat 106:447-452

Ridpath MG (1972) The Tasmanian native hen, Tribonyx morterii. II. The individual, the group and the population. CSIRO Wildl Res 17:53-90

Schaik CP van, Noordwijk MA van, Warsono B, Sutriono E (1983) Party size and early detection of predators in Sumatran forest primates. Primates 24:211-221

Skutch AF (1935) Helpers at the nest. Auk 52:257-273

Snowdon CT, Soini P (in press) The tamarins: Genus Saguinus. In: Mittermeier RA, Coimbra-Filho AF (eds) Ecology and behavior of neotropical primates, vol 2, Academia Brasileira de Ciencias, Rio de Janeiro

Sokal RR, Rohlf FJ (1981) Biometry. Freeman and Co, San Francisco

Stacey PB (1979) Kinship, promiscuity and communal breeding in the acorn woodpecker. Behav Ecol Sociobiol 6:53-66

Sussman RW, Kinzey WG (1984) The ecological role of the Callitrichidae: A review. Am J Phys Anthrop 64:419449

Terborgh J (1983) Five new world primates: A study in comparative ecology. Princeton University Press, Princeton NJ

Terborgh J, Goldizen AW (1985) On the mating system of the cooperatively breeding saddle-backed tamarin (Saguinus fuscicollis). Behav Ecol Sociobiol 16:293-299 